\title{
Unstable Genetic Transformation in Bacillus subtilis and the Mode of Inheritance in Unstable Clones
}

\author{
V. N. IYER \\ Microbiology Research Institute, Canada Department of Agriculture, Ottawa, Ontario, Canada
}

Received for publication 24 March 1965

\begin{abstract}
Iyer, V. N. (Canada Department of Agriculture, Ottawa, Ont., Canada). Unstable genetic transformation in Bacillus subtilis and the mode of inheritance in unstable clones. J. Bacteriol. 90:495-503. 1965.-An ultraviolet-induced mutant has been isolated from the double auxotroph of Bacillus subtilis (bearing the linked mutations $\operatorname{try}_{2}$ and $\left.h i s_{2}\right)$. This mutant has the property of yielding unstable transformants which, in the case of transformation to prototrophy, can be recognized by reduced colony size on minimal agar. Unstable transformant clones usually become stabilized early during the development of the clone (within 12 generations). Analyses of genotypes emerging from such clones on stabilization indicate that in some of these clones the exogenote is transmitted linearly; its integrity is sufficiently preserved that it can participate in two independent recombination events in two different cells. Genetic markers on the exogenote are expressed in situations where genetic integration has not occurred.
\end{abstract}

The current concept of genetic transformation mediated by deoxyribonucleic acid (DNA) is that a transformable strain of bacterium, when genetically competent to undergo transformation, irreversibly binds the transforming DNA and, by a process of recombination, incorporates into its own genome one or more genetic markers originally present in the donor molecule. Recent studies bearing on the recombination event indicate that, in both pneumococcus (Lacks, 1962; Fox and Allen, 1964) and in Bacillus subtilis (Bodmer and Ganesan, 1964), there is a physical incorporation of part of the donor molecule into the resident DNA of the recipient. The details of these events and the cellular physiological mechanisms that mediate them are unknown, but it has been shown (Iyer and Ravin, 1962) that the efficiency of such an incorporation can be determined by genetic factors in the recipient. It is therefore both pertinent and reasonable to attempt to isolate mutant strains that will be defective or inefficient in their ability to carry out those physiological functions that are associated with the recombination event, the hope being entertained that these strains would be useful tools in studies bearing on the biochemical details underlying the events. The isolation of one such strain of Bacillus subtilis which gives rise to unstable transformant clones is described in this paper. Further, and as a first step to its possible exploitation, the nature of cellular transmission of genetic markers originally present in the transforming molecule is established by clonal analyses.

\section{Materials and Methods}

Bacterial strains and genetic markers. All strains were originally derived from the indole-deficient strain 168 of Burkholder and Giles (1947), the genotype of which is referred to as $\operatorname{try} \mathrm{2}^{-}$, following Nester, Schafer, and Lederberg (1963). Table 1 lists the strains used, their genotype and origin. All strains, while being used either as recipients or donors, were examined for assurance of clonal purity of the characters in question. The major part of this study concerns a strain, designated $68 \mathrm{C}$, which, as will be described, was derived by ultraviolet-induced mutation from strain 31 (try ${ }_{2}$ $h_{i s_{2}}{ }^{-}$) of Ephrati-Elizur, Srinivasan, and Zamenhof (1961).

Transforming DNA. DNA was prepared from phenotypically homogenous populations of donor cells essentially by the procedure described by Marmur (1961).

Transformation procedures. Genetically competent populations were obtained by one of the following two basic procedures or modifications of them which are described where relevant in the following sections: (i) the procedure described by Anagnostopoulos and Spizizen (1961) was used, or (ii) a healthy, maximally turbid culture of the recipient strain in Difco nutrient broth (NB) was diluted $10^{6}$, and $0.05 \mathrm{ml}$ of this dilution (approximately 50 cells) was inoculated into $10.0 \mathrm{ml}$ of $\mathrm{NB}$ and incubated with shaking for $15 \mathrm{hr}$. The resultant culture was diluted fourfold in a minimal medium, and was reincubated with shaking for 3 
TABLE 1. Strains of Bacillus subtilis used as donor or recipient

\begin{tabular}{|c|c|c|}
\hline $\begin{array}{l}\text { Strain } \\
\text { no. }\end{array}$ & Genotype & $\begin{array}{l}\text { Source and alternate } \\
\text { designation, if any }\end{array}$ \\
\hline 1 & $t r y_{2}^{-}$ & Burkholder and Giles, 1947 \\
\hline 19 & $s t r-r$ & SB19; Nester et al., 1963 \\
\hline 26 & str-r mac-r 1 & Spontaneous mutation in 19 \\
\hline 68 & $\operatorname{try} y_{2}^{-h i s_{2}}-$ & $\begin{array}{l}\text { Ephrati-Elizur et al., } 961 \\
\text { (strain 31) }\end{array}$ \\
\hline $68 \mathrm{C}$ & $\operatorname{try}_{2}{ }^{-} h i s_{2}{ }^{-}$ & $\begin{array}{l}\text { Ultraviolet-induced muta- } \\
\text { tion in } 68\end{array}$ \\
\hline
\end{tabular}

hr to yield the competent culture. This latter procedure is a modification of a procedure described earlier (Opara - Kubinska, KuryloBorowska, and Szybalski, 1963) and will be referred to as the NB/VB regimen. Populations of competent cells obtained by either method were exposed to a concentration of transforming DNA in the linear-response region for a limited period $(30 \mathrm{~min})$, and the reaction was terminated by exposure to $\mathrm{Mg}^{++}$-activated pancreatic deoxyribonuclease (DNase) (Worthington, once crystallized). The two procedures gave comparable transformation frequencies and linkage patterns in the $\mathrm{try}_{2}^{-} \mathrm{his}_{2}^{-}$region (transformation frequency, 0.008 to $0.03 \%$, contransfer frequency, 45 to $55 \%$ ). Colonies were observed with a Wild M5 stereoscopic microscope.

Definitions. In all of the experiments and discussion to follow, genotype is defined as the genetic trait(s) that is transmissible from one clonally derived population to another by means of DNA extracted from the donor. Phenotype is defined as the trait that is expressed as colony-forming ability (visible but generally observed at a magnification of $\times 60$ ) on the defined medium. Exogenote is defined as that portion of the transforming DNA molecule that gains entry into a competent bacterium, and in the present experiments is recognized by its ability to express itself phenotypically. That part of the bacterial genome that is homologous to the exogenote is referred to as the endogenote after Morse, Lederberg, and Lederberg (1956). Integration denotes an event following which the marker is replicated geometrically at the pace of markers previously resident on the bacterial chromosome. A recombination event is one where the genotype of a recipient is altered by the integration of a marker(s) originally present in the donor molecule.

\section{Results}

Origin of unstable transformant clones. Bacterial cells of a recipient strain competent to undergo genetic transformation were exposed to transforming $\mathrm{DNA}$ in the linear-response region of a concentration curve for $30 \mathrm{~min}$; the exposure was terminated by DNase; the cells were washed twice by centrifugation, and were spread on a medium selective for transformants. Although the majority of colonies that arise on the selective medium are both genotypically and phenotypically stable and homogenous, a variable fraction of them are unstable for the trait examined, reverting either to the recipient phenotype and genotype or to a heterogenous state composed of cells with more than one phenotype and genotype. Assurance that clonal instability is in fact associated with the transformation events is obtained by the following observations. (i) Both donor and recipient populations are homogenous and stable for the characters to be specified, and the recipient strain does not spontaneously mutate to tryptophan or histidine independence at frequencies greater than $10^{-8}$. (ii) No prototrophs, either of a stable or unstable type, can be detected when recipient or donor cells are treated with homologous DNA. (iii) Although homologous DNA can compete with heterologous DNA and depress the frequency of total transformants arising at saturating DNA concentrations, it does not influence the proportion of unstable transformants. (iv) This proportion (unstable/ stable transformants) is not significantly influenced by the total number of colonies on a plate, as one may expect if syntrophic factors were operating. The type or types that arise on stabilization of the clone, genotypically and phenotypically, resemble the original recipient (most frequently) or (rarely) recombinants of the recipient and donor. Since the conditions under which unstable clones are observed exclude syntrophic effects, spontaneous mutation, or more than one round of reaction between transforming DNA and recipient cell, their origin is best attributed to a segregation phenomenon. This clonal instability has been observed for the strains and markers listed in Table 1. The low frequency with which unstable clones generally occur has, however, limited the detailed aspects of this study to the $\operatorname{rry}_{2}{ }^{-}$his ${ }_{2}^{-}$strain, $68 \mathrm{C}$.

Isolation of strain $68 C$. In some of our preliminary experiments involving the transformation of strain 68 [strain 31 of Ephrati-Elizur et al. (1961)] to prototrophy, it was frequently observed that a small fraction of the transformant colonies on minimal agar were minute in relation to the size of the majority of clones. An examination of the phenotypic composition of such colonies revealed that, in every case, prototrophic cells were conspicuously absent; that is, the phenotypically transformed prototrophs were, in fact, unstable. There was, in this observation, an analogy with the clones derived by phage-mediated transduction of Salmonella (Ozeki, 1956), although it may 
be noted that, in that situation, minute colonies constituted the majority of clones that appeared. In any event, the positive correlation between colony size and instability of transformants provided a means of selecting strains refractory to stable transformation.

Exponentially growing cells of strain 68 in NB were exposed to ultraviolet irradiation to secure 0.01 to $0.1 \%$ survival. Surviving colonyforming units were independently grown through the competency regimen, and $10^{5}$ to $10^{6}$ cells were spread on restricted areas on the surface of minimal agar containing $25 \mu \mathrm{g} / \mathrm{ml}$ of extracted DNA from a prototrophic strain. On incubation of the plates at $37 \mathrm{C}$ for $48 \mathrm{hr}$, one or two types of colonies appeared. The appearance and relative proportion of the minute-type colony was used as an index of unstable transformation. Strain $68 \mathrm{C}$ has been isolated in this manner after a limited screening of single-colony isolates from an ultraviolet-irradiated population of strain 68 . Of 60 isolates tested, $68 \mathrm{C}$ was the one that gave the highest frequency of minute colonies on transformation with prototrophic DNA. The possibility of isolating, by this means, a mutant capable of yielding even a higher frequency of unstable transformants than does $68 \mathrm{C}$, is one that needs to be examined. When competent cells of strain $68 \mathrm{C}$ are exposed to a limiting concentration of prototrophic DNA, they consistently give rise to two types of colonies distinguished on the basis of colony size on minimal agar (Fig. 1). The larger colonies (average diameter, $1.2 \mathrm{~mm}$ ) are usually, but not always, composed of stable

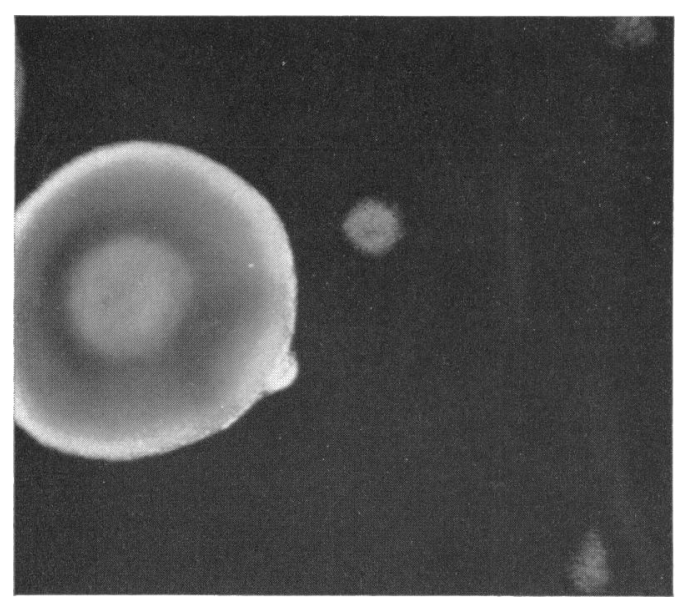

FIg. 1. Colonies of stable transformants (large) and unstable transformants (minute) arising on minimal agar from the transformation of strain $68 \mathrm{C}$ by prototrophic DNA. Incubation: $48 \mathrm{hr}$ at $37 \mathrm{C}$. $\times 30$. prototrophic colony-forming units. Rarely $(0.2 \%$ or less), they may consist of cells that are no longer prototrophic. In contrast, minute colonies (average diameter, $0.2 \mathrm{~mm}$ ) have always been found to be homogeneously auxotrophic or composed of a mixture of auxotrophic and prototrophic cells. A reproducible and relatively high proportion (10 to $40 \%$ ) of minute colonies is obtained by using different samples of a single competent batch of $68 \mathrm{C}$ cells maintained frozen with $5.0 \%$ glycerol. This proportion is more variable $(0.5$ to $40.0 \%)$ when $68 \mathrm{C}$ is cycled through nutrient agar. In one experiment, the transformed cells were spread on minimal media supplemented with DNase $\left(100 \mu \mathrm{g} / \mathrm{ml}, \mathrm{Mg}^{++}\right.$ activated). No alteration in the proportion of minute colonies was observed.

Cellular aggregation. When strain $68 \mathrm{C}$ was grown to competence in the NB-VB regimen, 5.0 to $20.0 \%$ of the cells occurred in pairs or, rarely, in larger clusters. Stirring the bacterial suspension in the cold for $2 \mathrm{~min}$ at 22,000 to 24,000 $\mathrm{rev} / \mathrm{min}$ in a Virtis homogenizer reduced the proportion of clusters without markedly reducing viability.

To evaluate the possible influence of aggregation, the proportion of unstable clones arising from a transformed population before and after homogenization was examined. The results of such an experiment (Table 2) indicate that a 12 fold reduction in the proportion of cells occurring in clusters had no observable effect on the proportion of unstable clones. Factors other than those influencing cellular aggregation must therefore be sought to explain the observed instability.

Heterokaryotic and heterogenotic states. Exponentially growing cells of $B$. subtilis are known to carry an average of three chromatin bodies (Ganesan, unpublished data). The occurrence of a heterokaryotic state in populations undergoing genetic transformation must therefore be con-

TABLE 2. Effect of reducing cell clusters on the frequency of unstable clones arising from the transformation of strain $68 \mathrm{C}\left(\mathrm{try}_{2}{ }^{-} \mathrm{his}_{2}{ }^{-}\right)$by DNA from prototrophic cells

\begin{tabular}{c|c|c}
\hline $\begin{array}{c}\text { Viable colony- } \\
\text { forming units on } \\
\text { nutrient agar } \\
\left(\times 10^{6}\right)\end{array}$ & $\begin{array}{c}\text { Per cent of cells } \\
\text { occurring in } \\
\text { clusters* }\end{array}$ & $\begin{array}{c}\text { Proportion of clones } \\
\text { examined that } \\
\text { display instability }\end{array}$ \\
\hline 7.2 & 18.2 & $17 / 30$ \\
4.2 & 5.8 & \\
3.9 & 4.2 & $19 / 30$ \\
1.9 & 1.5 & 1.5 \\
\hline
\end{tabular}

* Estimated by microscopic examination of smears stained to demonstrate cell walls (Robinow and Murray, 1953). 
sidered as a possibility which cannot be rigidly excluded in every case. Two arguments will be advanced to exclude heterokaryosis in specific clones: the observed emergence in specific instances of more than one recombinant type from a single prototrophic clone (arising after a limiting exposure to transforming DNA), and the occurrence on minimal agar of clones which in fact are composed exclusively of a partial auxotroph $\left(\operatorname{try}{ }_{2}{ }^{+} h i s_{2}{ }^{-}\right.$or $\left.\operatorname{try}{ }_{2}-h i s_{2}{ }^{+}\right)$.

Stabilized genotypes from unstable prototrophic clones. As a rule, unstable prototrophic clones arising from the transformation of strain $68 \mathrm{C}$ become stabilized within 13 to 16 generations after exposure to DNA. This is inferred from the number of viable cells that constitute individual minute colonies and from the fact that no further segregation occurs from the phenotypes emerging from such minute and initially unstable prototroph. When an unstable clone becomes stabilized and homogenous by segregation, the genotypes that appear $\left(\operatorname{try}{ }_{2}^{-} h i s_{2}^{-}, \operatorname{try}_{2}{ }^{+} h \mathrm{his}_{2}{ }^{-}\right.$, try $y_{2}{ }^{-} h i s_{2}{ }^{+}$, or $\operatorname{try} y_{2}^{+} h i s_{2}{ }^{+}$) are always similar to the original ones that entered into the cross or to recombinations of them. This was determined by using such stabilized populations as donors or recipients in transformation experiments. For instance, a $\mathrm{try}_{2}-\mathrm{his}_{2}-$ segregant would be transformed by a DNA preparation to stable prototrophy at efficiencies comparable with the original recipient; DNA from this segregant would be ineffective in transforming the original recipient. The composition of different types of unstable prototrophic clones arising from the transformation of strain $68 \mathrm{C}$ is indicated in Tables 3 and 4. Clones of types 1 and 4, with an initially prototrophic phenotype but homogeneously consisting of a complete or partial auxotrophic genotype, constitute a large majority of the unstable types. It is highly improbable that they could arise from heterokaryons and, since syntrophy is excluded, their occurrence could imply a heterogenotic state. Heterokaryosis cannot be excluded in clones of type 2 , but is clearly excluded in clones of type 3 that are composed of more than one recombinant type. The occurrence of this type is of interest, suggesting as it does that two independent recombination events occurred within the confines of a single transformed clone emerging from a limiting exposure to transforming DNA. In the following experiments, I focus on clones of this type. Specifically, I wish to draw attention to the proportion of different recombinant types that could be expected and those that are in fact observed.

Transmission of the exogenote in heterogenotes. I suggest that the rare clones consisting of more
TABLE 3. Qualitative composition (stabilized genotypes) issuing from unstable clones on minimal agar from the cross try ${ }_{2}^{-}$his $_{2}^{-} \times$try $_{2}{ }^{+}{ }^{-}$is $_{2}{ }^{+}$

(listed in the relative order of frequency with which such clones were detected)*

\begin{tabular}{|c|c|c|}
\hline $\begin{array}{c}\text { Clonal } \\
\text { typet }\end{array}$ & Genotypic composition & $\begin{array}{l}\text { No. of clones of } \\
\text { given composition }\end{array}$ \\
\hline $\begin{array}{l}1 \\
4 \\
4 \\
2 \\
2 \\
2 \\
3\end{array}$ & 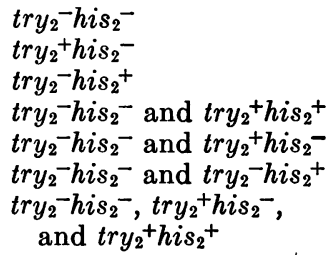 & $\begin{array}{l}10+32=42 \\
5+12=17 \\
5+10=15 \\
3 \\
2 \\
2 \\
2\end{array}$ \\
\hline
\end{tabular}

* Compiled from different experiments. Boldface numbers indicate clones where genotype was established by preparing transforming DNA and making the appropriate crosses. Light-face numbers are clones whose genotypes are inferred from the stabilized nature of their phenotype.

$\dagger$ Numbers refer to clonal types illustrated in Fig. 4.

TABLE 4. Composition of 10 selected unstable clones consisting of two recombinant genotypes*

\begin{tabular}{|c|c|c|}
\hline $\begin{array}{l}\text { Clonal } \\
\text { typet }\end{array}$ & $\begin{array}{l}\text { Genotypes present and } \\
\text { their proportion }\end{array}$ & $\begin{array}{c}\text { No. of } \\
\text { clones of } \\
\text { indicated } \\
\text { type }\end{array}$ \\
\hline 3 & $\begin{array}{l}\operatorname{try} y_{2}^{-} h i s_{2}^{-}, \operatorname{try}_{2}{ }^{+} h i s_{2}-\text {, and } \\
\quad \operatorname{tr} y_{2}+h i s_{2}{ }^{+}(0.3: 0.7: 0.01)\end{array}$ & 5 \\
\hline 3 & $\begin{array}{l}\operatorname{try}_{2}^{-}{ }^{-} i s_{2}^{-}, \operatorname{try}_{2}{ }^{+} h i s_{2}^{-}, \text {and } \\
\quad t r y_{2}{ }^{+} h i s_{2}+(0.3: 0.5: 0.3)\end{array}$ & 2 \\
\hline 3 & $\begin{array}{l}\operatorname{tr} y_{2}^{-}{ }^{-} i s_{2}^{-}, \operatorname{try}_{2}-h i s_{2}{ }^{+}, \text {and } \\
\quad \operatorname{try}{ }_{2}^{+} h i s_{2}^{+}(0.3: 0.6: 0.1)\end{array}$ & 2 \\
\hline 5 & $\begin{array}{l}\operatorname{try}_{2}{ }^{+} h i s_{2}^{-} \text {and } \operatorname{try} y_{2}+h i s_{2}{ }^{+} \\
\quad(1.0: 0.01)\end{array}$ & 1 \\
\hline
\end{tabular}

* All clones were derived from a single experiment, which involved a limited exposure of strain $68 \mathrm{C}$ to a subsaturating concentration of transforming prototrophic DNA and selection on minimal agar from which clones were examined after $48 \mathrm{hr}$ of incubation at $37 \mathrm{C}$.

$\dagger$ Numbers refer to clonal types illustrated in Fig. 4 .

than one recombinant type arise by one of the following models, which are represented diagrammatically in Fig. 2. (i) The persistent exogenote (or a genetically determinative portion of it) was transmitted linearly but participated in two recombination events; that is, that portion of the exogenote that did not participate in the first recombination event was conserved and transmitted linearly so as to participate in a second recombination event. (ii) The exogenote, in per- 


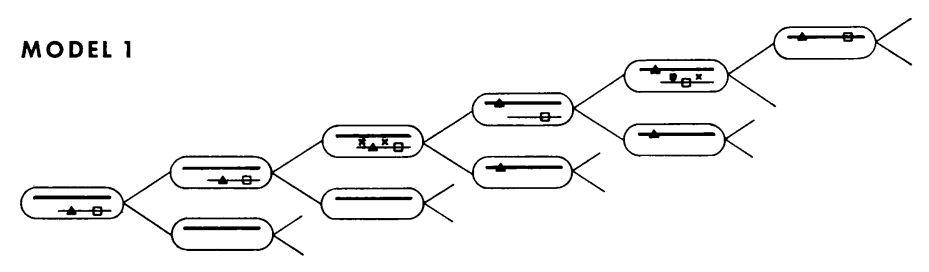

MODEL 2

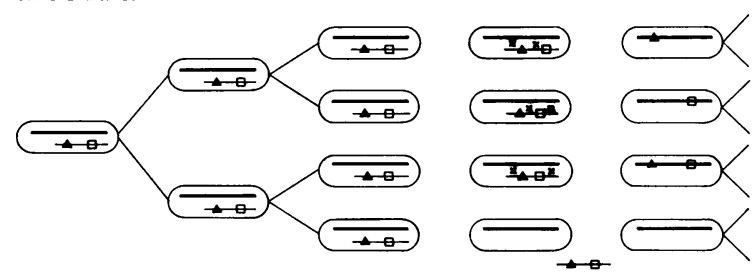

FIG. 2. Diagrammatic representation of two models by which the unstable transformants could have originated. $\mathbf{\Delta}$, try $_{2} ; \square, h_{i s_{2}} ; \times$, location of recombination events leading to marker integration; $<$, further geometric transmission of markers with cell duplication.

sisting, replicated for a limited number of generations; copies of the exogenote thus became available for independent recombination events in different cells.

According to the first model, the first recombination event may serve to incorporate one of the two donor markers, $\operatorname{try}_{2}{ }^{+}$or $\mathrm{his}_{2}{ }^{+}$. The unincorporated marker is transmitted unilinearly, its incorporation being deferred to another cell in the line. As a result of this manner of transmission, it should not be possible to obtain a mixed clone composed of the recombinant genotypes $\operatorname{try}_{2}{ }^{+} h i s_{2}{ }^{-}$and $t r y_{2}{ }^{-} h i s_{2}{ }^{+}$, and all clones consisting of more than one recombinant type must have $\operatorname{try}_{2}{ }^{+} \mathrm{his}_{2}{ }^{+}$as one of the components. The assumption is being made here that recombinations occurring during transformation are nonreciprocal in nature. The validity of this assumption rests on the absence of any evidence of lethality during transformation and on the fact that one does not find reciprocal recombinant types in transformation. The origin of the recipient genotype (try $\left.{ }_{2}^{-} h i s_{2}^{-}\right)$which is frequently a third component of such clones is also indicated in Fig. 2. In contrast, according to the second model, one would expect mixed clones of the type try ${ }_{2}{ }^{+} h i s_{2}-$ and $t r y_{2}^{-} h i s_{2}{ }^{+}$to occur with a frequency predictable from the relative probability of genetic incorporation of the markers $t r y_{2}{ }^{+}$and $h_{i s}{ }^{+}$.

A large number of minute colonies arising on minimal agar after a limited exposure of $68 \mathrm{C}$ to a subsaturating concentration of prototrophic DNA were picked off with a straight wire, suspended in $1.0 \mathrm{ml}$ of $\mathrm{NB} / \mathrm{VB}$ supplemented with $5.0 \%$ glycerol, and frozen. The composition of each colony was examined by thawing its suspension, washing free from glycerol, and spreading samples on minimal agar (M) and minimal agar supplemented with L-tryptophan (MT) or L-histidine $(\mathrm{MH})$, or both (MTH). In the same experiment, the frequency of stable transformants to tryptophan or histidine independence (or both) was determined in relation to stable macrolide-resistant transformants (marker mac-r1, which is unlinked to $\operatorname{try}_{2}$ or $h i s_{2}$. The ratio $\operatorname{try}_{2}{ }^{+} h i s_{2}{ }^{-} /$ mac-r1 : $\operatorname{try}_{2}{ }^{-}$his ${ }_{2}^{+} /$mac-r $1: \operatorname{tr} y_{2}{ }^{+}$his $_{2}{ }^{+} /$mac- $r 1$ provided the measure of the probability of incorporation of $t r y_{2}{ }^{+}$and $\mathrm{his}_{2}{ }^{+}$, and in this specific experiment approximated $2: 1: 2$.

A total of 450 minute colonies was examined, and all of these represented unstable transformations. Since previous experiments (Table 3) had indicated that only a small proportion of these colonies are composed of more than one recombinant genotype, the suspensions were, for convenience, first subjected to a preliminary screening which consisted of spreading $0.1 \mathrm{ml}$ of each on MT and MH. Only those suspensions which gave rise to colonies on both media were subjected to a further detailed examination. (It may be noted that this experimental expedient places a lower limit on the detection of colonies bearing two or more recombinant types; the occurrence of a recombinant type at frequencies $<0.0012$ of the total cells within a clone would have gone undetected by this procedure.) The clonal composition of colony suspensions bearing cells capable of growth on both media were further examined in detail by spreading samples in duplicate on $\mathrm{M}$, 
MT, MH, and MTH. Forty-five such colonies were detected; of these, only 10 bore cells of two different recombinant types, the remaining clones being of type 2 in Table 3 . The composition of these 10 clones is indicated in Table 4 . They show that: in every unstable clone containing two recombinant types, recombinants that integrated both markers are present and constitute the minority type; no unstable clone containing the recombinant types $t r y_{2}{ }^{+} h i s_{2}{ }^{-}$and $\operatorname{try}_{2}-\mathrm{his}_{2}{ }^{+}$was detected. These results together make the operation of model 2 extremely unlikely. Cells from which all such clones originated clearly received both markers, but from none of them did a $t r y_{2}{ }^{+} h i s_{2}{ }^{-}$and $t r y_{2}-h_{i s_{2}}{ }^{+}$segregate. What is the probability of finding such clones according to model 2? Even if one assumes that the integration of markers is not altered by the mechanisms by which unstable clones arise, the probability of obtaining such a clone would be given by probability $(P)$ for integrating:

$\operatorname{tr} y_{2}$ alone (giving rise to $\operatorname{tr} y_{2}{ }^{+} h \mathrm{~s}_{2}-=2 / 5$

$h i s_{2}$ alone (giving rise to $\operatorname{tr} y_{2}^{-} h i s_{2}{ }^{+}=1 / 5$

$t r y_{2}$ and $h i s_{2}$ (giving rise to $\operatorname{try}_{2}{ }^{+} h i s_{2}{ }^{+}$) $=2 / 5$

$P$ for obtaining mixed clones of the type:

1. $\operatorname{try}_{2}{ }^{+} h i s_{2}-$ and $t r y_{2}-h i s_{2}{ }^{+}=2 / 5+1 / 5=$ $3 / 5$

2. $\operatorname{try}_{2}+h i s_{2}-$ and $\operatorname{try} \mathrm{y}_{2}+h i s_{2}+=2 / 5+2 / 5=$ $4 / 5$

3. $\operatorname{try}_{2}{ }^{-} h i s_{2}{ }^{+}$and $t r y_{2}{ }^{+} h i s_{2}{ }^{+}=1 / 5+2 / 5=$ $3 / 5$

$P$ for obtaining mixed clones of type 1 among all mixed clones examined $=0.3$. Since the emergence of such a clone was not detected in 10 trials, the first model is clearly the favored one, the probability of mistakenly accepting it even under such assumptions being $(7 / 10)^{10}=0.028$. It may also be recalled that in Stocker's (1963) experiments, which involved the micromanipulative isolation of transformant phenotypes from the cross $\operatorname{tr} y_{2}-h i s_{2}{ }^{+} \times \mathrm{DNA}_{\text {try }}{ }^{+} h i \mathrm{~s}_{2}{ }^{-}$, when a prolonged period of serial growth on two complete media intervened between the detection of a phenotypically transformed cell and the analyses of clones arising from it, three rare clones were observed in which two different recombinant types were represented. In none of these three clones was a mixture of $t r y_{2}{ }^{+} h i s_{2}{ }^{+}$and $\operatorname{try} y_{2}{ }^{-} h i s_{2}{ }^{-}$ detected, which would again seem to support our first model.

Linear transmission of characters determined by exogenote. Acceptance of the first model clearly implies that the exogenote is transmitted linearly. I sought to demonstrate this more directly by (i) following, as a function of time, the segregation of a character determined by the exogenote during the further growth of phenotypically transformed clones in a nonselective liquid medium, and (ii) by respreading experiments of the type performed by Ozeki (1956) in demonstrating abortive transduction in Salmonella. As has already been pointed out, two features of unstable transformant clones which differ from the transduction heterogenotes of Salmonella (Ozeki, 1956) or Escherichia coli (Morse et al., 1956) are that in any one experiment unstable transformant clones have always occurred at a lower frequency than stable transformants, and that stabilization of the clone by segregation occurs early during clonal development so that by the time a visible minute colony on $M$ agar is examined segregation is usually complete. A minute $\mathrm{M}$ agar colony on further examination seldom yields colonyforming units on M agar, and such units when they arise most often constitute a small fraction of the total cells that comprise a colony (Tables 3 and 4). In respreading experiments involving $M$ agar, there was an early decline in the number of minute colonies that arose on respread plates, indicating that stabilization of the components of the clone occurred during the early stages of colony development. Linear transmission of a donor-determined property was, however, observed in one instance, involving an erythromycin-resistance marker (mac-r1). In this experiment, $68 \mathrm{C}$ was transformed to erythromycin resistance by DNA extracted from strain 26 , and the population was spread on nutrient agar containing erythromycin $(0.5 \mu \mathrm{g} / \mathrm{ml})$. Suspensions of 250 colonies arising on the medium in $20 \mathrm{hr}$ at $37 \mathrm{C}$ were spotted on erythromycinagar to detect instability, such suspensions being then frozen with $5.0 \%$ glycerol until further examination. Of the colonies, $12 \%$ showed no growth on the spotted area indicating instability. Their suspensions were washed free from glycerol and inoculated into NB. At intervals of growth in broth, suitable dilutions of the suspensions were spread on nutrient agar and erythromycin-agar. In only 1 of the 30 colony suspensions examined in this manner were viable erythromycin-resistant cells detected, and in this suspension the further transmission of erythromycin resistance was linear over a period of nearly three decades of growth (Fig. 3).

\section{Discussion}

There is now general agreement that, in all of the three transformation systems that have been studied (Fox, 1962; Fox and Hotchkiss, 1962; Lacks, 1962; Voll and Goodgall, 1961; Lorkiewicz, Opara-Kubinska, and Szybalski, 1961; 


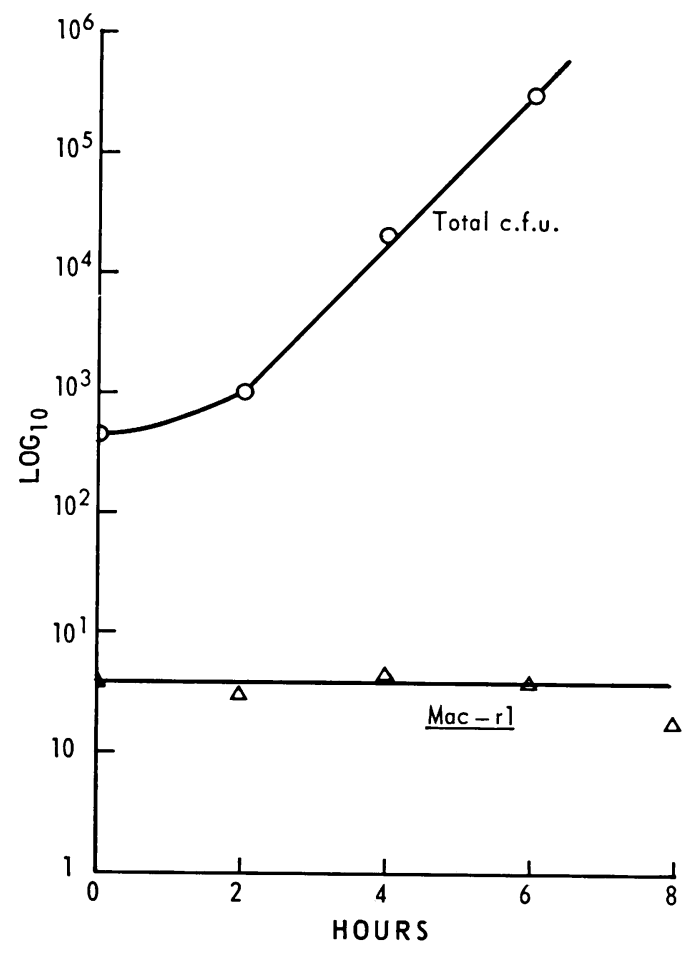

FIG. 3. Further linear transmission under nonselective conditions of erythromycin resistance (conferred by marker mac-rl) in an unstable clone which arose on nutrient agar plus $0.5 \mu \mathrm{g} / \mathrm{ml}$ of erythromycin.

Bodmer and Ganesan, 1964), the event of recombination most often occurs soon after INA uptake and perhaps even before the first cell division. Although it has been sometimes discounted (Schaeffer, 1964), the possibility that recombination can occasionally be deferred for a limited number of generations has been previously considered, on the basis of observations with pneumococcus (Ravin, 1960; Hotchkiss, 1956). The present observation that certain unstable transformant clones of $B$. subtilis on stabilization give rise to two recombinant types to the exclusion of a third possible recombinant type lends credence to such considerations. Furthermore, since the probability that an exogenote will participate in a single recombination event is much greater than that of its participating in two independent events, I believe that many of our unstable clones from which only one recombinant type could be recovered could also have arisen by a similar process. The possible origin by this means of all the clonal types I observed is summarized in Fig. 4. It is also possible that, in some of the unstable clones bearing a single recombinant type, it was some product of the exogenote rather than the exogenote itself that was being transmitted. This latter interpretation is favored by Stocker (1956) to explain some of his abortively transduced motile clones of Salmonella. In the case of transformation, although emphasizing that these two interpretations are not mutually exclusive for clones bearing only a single recombinant type, the latter interpretation cannot be invoked for the clones bearing two recombinant types.

Evidence from other laboratories (Bodmer and Ganesan, 1964; Szybalski, 1961; Fox and Allen, 1964) indicates that recombination during genetic transformation involves a physicochemical scission and repair mechanism mediated presumably by physiological factors in the recipient. Strain $68 \mathrm{C}$ could be deficient in one or more of such factors. On the other hand, the recombination refractivity of the strain could be conceived to have a basis in imposed genetic pairing difficulties between the donor fragment and the bacterial chromosome. This latter possibility does not, however, appear to be the likely one, because the observed "instability" is not local to the $t r y_{2} h i s_{2}$ region but extends to mutations such as mac-rl and str-r which are unlinked to $\operatorname{try}_{2} h i s_{2}$. Furthermore, when $68 \mathrm{C}$ is singly transformed to tryptophan or histidine independence, such transformants continue to yield unstable prototrophs when they are in turn themselves transformed.

A basis of similarity in the intracellular process accompanying transformation and transduction is that genetic determinants borne by a transforming molecule or transducing particle can express themselves phenotypically without necessarily being integrated with the bacterial chromosome. There has been some question about this (Lacks and Hotchkiss, 1960), but the present observations and those of Stocker (1963) in B. subtilis and of Hotchkiss (1956) and of Ravin (1960) in pneumococcus are in accord with this belief. Since phage-mediated transduction has now been demonstrated in strains closely related to those used in the present study (Thorne, 1962; Takahashi, 1963), this provides one with the opportunity to examine whether transduction and transformation heterogenotes occur in one and the same system and whether differences in the rate of segregation from heterogenotes are a consequence of the mode of gene transfer or a property inherent in the recipient bacterium.

The availability of strains such as $68 \mathrm{C}$, in which a heterogenotic state can be established, should permit the functional analyses of phenotypically similar mutations and the analysis of 
CROSS: RECIPIENT A- B- $\times$ DONOR A+B+

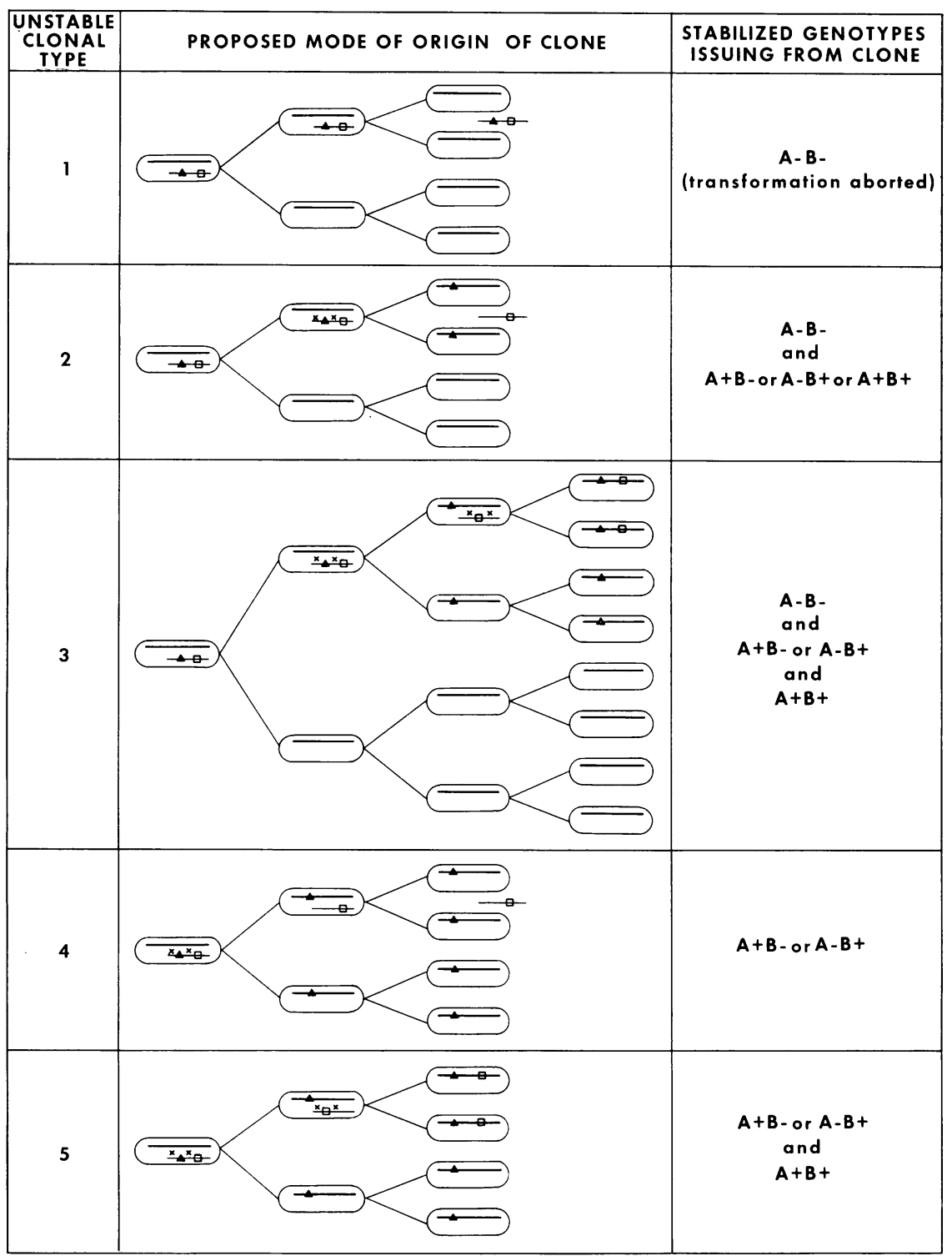

FIG. 4. Diagrammatic representation of the probable mode of origin of all the detected clonal types according to model 1 of Fig. 3. The recombinant type $A+B-$ or $A-B+$ would arise by the genetic integration of the region comprising one of the two sites, $A$ or $B$, to the exclusion of the other. Recombinant type $A+B+$ would arise by integration of the entire $A+B+$ region.

dominance relationships. In the present study, since instability of transformant clones was also observed for a streptomycin-resistance and an erythromycin-resistance marker (Table 1), we may already infer that, in $B$. subtilis, the ability to survive exposure to streptomycin and erythromycin are dominant to sensitivity.

\section{ACKnowledgments}

I appreciatively acknowledge the joint comments of Arnold Ravin and Elaine Ache on the manuscript, and I am grateful to Susan Becker and U. St. Jacques for technical assistance. Contribution No. 584 from the Microbiology Research Institute, Research Branch, Canada Department of Agriculture, Ottawa. 


\section{Literature Cited}

Anagnostopoulos, C., and J. Spizizen. 1961. Requirements for transformation in Bacillus subtilis. J. Bacteriol. 81:741-746.

Bodmer, W. F., and A. T. Ganesan. 1964. Biochemical and genetic studies of integration and recombination in Bacillus subtilis transformation. Genetics 50:717-738.

Burkholder, P. R., and N. H. Giles. 1947. Induced biochemical mutations in Bacillus subtilis. Am. J. Botany 34:345-348.

Ephrati-Elizur, E., P. R. Srinivasan, and S. ZAMenhoF. 1961. Genetic analysis by means of transformation, of histidine linkage groups in Bacillus subtilis. Proc. Natl. Acad. Sci. U.S. $47: 56-63$.

Fox, M. S. 1962. The fate of transforming deoxyribonucleate following fixation by transformed bacteria. III. Proc. Natl. Acad. Sci. U.S. 48: 1043-1048.

Fox, M. S., And M. K. Allen. 1964. On the mechanism of deoxyribonucleate integration in pneumococcal transformation. Proc. Natl. Acad. Sci. U.S. 52:412-419.

Fox, M. S., AND R. D. Hotchkiss. 1960. Fate of transforming deoxyribonucleate following fixation by transformable bacteria. Nature 187: 1002-1006.

Hoтchkiss, R. D. 1956. The genetic organization of the deoxyribonucleate units functioning in bacterial transformations, p. 119-130. In $\mathrm{O}$. H. Gaebler [ed.], Enzymes: units of biological structure and function. Academic Press, Inc. New York.

IYER, V. N., AND A. W. RAviN. 1962. Integration and expression of different lengths of DNA during transformation of pneumococcus to erythromycin resistance. Genetics 47:13551363.

LACKS, S. 1962. Molecular fate of DNA in genetic transformation of pneumococcus. J. Mol. Biol. 5:119-131.

LACKs, S., AND R. D. Hotchkiss. 1960. A study of the genetic material determining an enzyme activity in pneumococcus. Biochim. Biophys. Acta 39:508-517.

Lorkiewicz, Z., Z. Opara-Kubinska, AND W. SzYBALSKI. 1961. Molecular fate of transforming DNA. Federation Proc. 20:360.
MARMUR, J. 1961. A procedure for the isolation of deoxyribonucleic acid from microorganisms. J. Mol. Biol. 3:208-218.

Morse, M. L., E. M. Lederberg, and J. LederBERG. 1956. Transductional heterogenotes in Escherichia coli. Genetics 41:758-779.

Nester, E. W., M. Schafer, and J. Lederberg. 1963. Gene linkage in DNA transfer: a cluster of genes concerned with aromatic biosynthesis in Bacillus subtilis. Genetics 48:529-551.

Opara-Kubinska, Z., Z. Kurylo-Borowska, AND W. SzY BALSKI. 1963. Genetic transformation studies. III. Effect of ultraviolet light on the molecular properties of normal and halogenated deoxyribonucleic acid. Biochim. Biophys. Acta $72: 298-309$

OzeKI, H. 1956. Genetic studies with bacteria. Carnegie Inst. Wash. Publ. 612, p. 97.

Ravin, A. W. 1960. Linked mutations borne by deoxyribonucleic acid controlling the synthesis of capsular polysaccharide in pneumococcus. Genetics 45:1387-1404.

Robinow, C. F., and R. G. E. Murray. 1953. The differentiation of cell wall, cytoplasmic membrane and cytoplasm of gram positive bacteria by selective staining. Exptl. Cell Res. $4: 390-407$.

SCHAEFFER, P. 1964. Transformation, p. 87-153. In I. C. Gunsalus and R. Y. Stanier [ed.], The bacteria, vol. 5. Academic Press, Inc., New York.

STOCKER, B. A. D. 1956. Abortive transduction of motility in Salmonella; a non-replicating gene transmitted through many generations to a single descendant. J. Gen. Microbiol. 15:575.

Stocker, B. A. D. 1963. Transformation of Bacillus subtilis to motility and prototrophy: micromanipulative isolation of bacteria of transformed phenotype. J. Bacteriol. 86:797804.

SzyBalski. W. 1961. Molecular fate of transforming DNA. J. Chim. Phys. 58:1098-1099.

TAKahashi, I. 1963. Transducing phages for $\mathrm{Ba}$ cillus subtilis. J. Gen. Microbiol. 31:211-217.

Thorne, C. B. 1962. Transduction in Bacillus subtilis. J. Bacteriol. 83:106-111.

Voll, M. J., and S. H. Goodgal. 1961. Recombination during transformation in Hemophilus influenzae. Proc. Natl. Acad. U. S. 47:505-512. 